
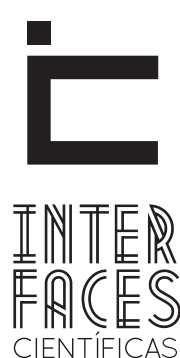

EDUCAÇÃO

ISSN IMPRESSO 2316-333X

E-ISSN 2316-3828

DOI-10.17564/2316-3828.2017v5n3p123-134

\title{
AS MULHERES REPRESENTADAS NOS LIVROS DIDÁTICOS: HISTÓRIA DO BRASIL
}

\author{
WOMEN REPRESENTED IN TEXTBOOKS: BRAZIL HISTORY \\ LAS MUJERES REPRESENTADAS EN LOS LIBROS DITÁCTICOS: HISTORIA DE BRASIL
}

\section{RESUMO}

O presente estudo busca analisar como são representadas as mulheres, nos livros didáticos do ensino de História do Ensino Médio. Enquanto objeto material de pesquisa foram utilizados três livros didáticos publicados nas décadas de 1970, 1980 e no ano de 2006, de modo a compreender as rupturas e permanências nessas representações e, de certo modo, no ensino de História. Este trabalho procurou mostrar como esses discursos foram se modificando e como a questão da (in)visibilidade das mulheres pode ser abordada nas aulas de História. Pode-se observar como a produção historiográfica com a temática sobre as mulheres foi alcançando novos objetos e novas abordagens que antes eram invisíveis na História.

\section{PALAVRAS-CHAVE}

História das mulheres. Livros didáticos. Ensino de História. Representações. 


\section{ABSTRACT}

The present study investigates how examine how women are depicted in textbooks of high school history teaching. While research material object we used three textbooks published in the 1970, 1980 and the year of 2006, in order to understand the ruptures and continuities in these representations and in teaching History. This paper sought to show how these speeches were changing and how the question of (in)visibility of women can be discussed in history classes.
One can observe how the historical production with the theme of women was reaching new objects and new approaches that were invisible in History.

\section{KEYWORDS}

History of women. Textbooks. History teaching.

Representations.

\section{RESUMEN}

El presente estudio pretende examinar cómo las mujeres están representadas en los libros didácticos de historia en la educación secundaria. Como objeto material de la investigación, se utilizaron tres libros didácticos publicados en los años 1970, 1980 y el año de 2006, con el fin de comprender las rupturas y la permanencia en estas representaciones y en la enseñanza de la historia. Este trabajo intentó demostrar cómo estos discursos fueron cambiando y cómo puede abordarse la cuestión de la (in)visibilidad de las mujeres en las lecciones de la historia. Se puede observar cómo la producción historiográfica con el tema de la mujer alcanzaba nuevos objetos y nuevos enfoques que eran invisibles en la historia.

\section{PALABRAS CLAVE}

Historia de las mujeres. Libros didácticos. Enseñanza de la historia. 


\section{INTRODUÇÃO}

As mulheres nunca estiveram ausentes da história, ainda que a historiografia tradicional, durante décadas, as tenha excluído. As mulheres, pela sua representação no decorrer da história, foram tornadas invisíveis, ou ainda representadas, apenas exercendo papéis secundários. Contudo, as mulheres tiveram participação ativa e relevante, elas não estiveram ausentes da história como se acreditava a partir da historiografia existente; considerando as mudanças ocorridas na historiografia em relação à história das mulheres, o presente estudo objetiva analisar como ocorreram alguns desdobramentos nos livros didáticos, bem como as representações das mulheres nesses livros. Busca-se compreender de que modo as mulheres ganharam (ou não) visibilidade na produção didática contemporânea.

Na realização do estudo buscou-se também refletir sobre a história das mulheres, utilizando como fonte de pesquisa livros didáticos, de modo que fosse possível compreender quais as representações das mulheres nesses livros didáticos, bem como refletir sobre essas representações no contexto do ensino de História. Foram utilizados, portanto, três livros didáticos do Ensino Médio. Os exemplares foram escolhidos pelo ano de publicação e livros que fossem voltados para o ensino médio.

A escolha dos livros não foi aleatória, e partiu da curiosidade das pesquisadoras em estudar três décadas diferentes com o objetivo de analisar como as mulheres foram representadas e como foram inseridas no processo histórico, com a pretensão de compreender as relações que se constituem nos diferentes tempos e espaços. A escolha pelas publicações de livros de três décadas diferentes foi necessária para acompanhar as mudanças historiográficas presentes nos livros didáticos e como eles abordam a história das mulheres, sendo os critérios de escolhas pautadas na listagem das editoras de maior expressão no mercado do livro didático (bloco das dez primeiras) segundo o Plano Nacional do Livro Didático (PNLD) e ano de publicação.
A sistematização dos dados contempla os períodos mais facilmente identificáveis pela organização dos próprios livros didáticos, que contemplam os três principais períodos políticos da história brasileira: Colônia, Império e República. Em primeiro lugar, foram sistematizados fichamentos a partir da leitura flutuante (BARDIN, 1977) das obras, registrando-se todas as menções a figuras ou representações femininas existentes nos livros didáticos estudados.

Após, esquematizou-se um fichamento global, onde emergiram quatro categorias generalizadas de "aparições" femininas no conteúdo dos livros: 1) Mulheres indígenas; 2) Escravas africanas ou afrodescendentes; 3) Membros de linhagens reais e; 4) Outras. Esta última categoria consubstancia uma diversidade de sujeitos, em geral figuras femininas relacionadas a movimentos artístico-culturais e personagens da história, cuja presença é mais frequente nos livros didáticos das décadas mais recentes.

Desta forma, são igualmente recortadas as localizações temporais das citações selecionadas. A análise das obras foi operacionalizada a partir da observação da forma como estes aparecimentos (ou esquecimentos) foram tratados pelos livros didáticos de história que compõem a amostra. Colocando em termos mais gerais, se o presente estudo buscou compreender "como" aparecem as identidades de gênero femininas e o que dizem sobre as relações de gênero em cada uma das obras.

Assim, pretende-se compor linhas iniciais da forma como foram "impostos" determinados papéis de gênero na escolarização, justificados e legitimados pelo ensino de história, destacando que o livro didático se converte, ao fim e ao cabo, num importante veículo portador de um sistema de valores que reforça concepções e atitudes ao mesmo tempo em que discrimina entre o que deve ser aceito e o que deve ser rejeitado, entre o que deve ser lembrado e o que deve ser esquecido pelos alunos no decorrer da sua formação escolar (BITTENCOURT, 2002).

De acordo com essa consideração, buscou-se verificar, neste artigo, a forma pela qual a História das Mulheres foi representada em livros didáticos da 
década de 1970, 1980 e 2006. Foram registradas todas as menções que fizeram referência às mulheres nesses livros e observou-se a forma que elas foram aparecendo ou sendo esquecidas. Buscou-se também neste estudo verificar a forma com as quais os livros didáticos trazem as informações textuais a respeito dos conteúdos históricos que relatam sobre a história das mulheres. Dessa forma, pretendeu-se verificar como a representação feminina foi imposta na escola e legitimadas pelo ensino de história.

Ao longo dos anos, na historiografia tradicional, ou seja, a História que enfatiza os grandes homens e seus feitos, as mulheres foram, em sua grande maioria, excluídas. Destaca-se que isso não se refere apenas à história do Brasil, mas, basicamente a toda a historiográfica de perspectiva eurocêntrica. Somente com a Escola de Annales, mais propriamente com a perspectiva conhecida Nova História é que se tem a possibilidade de trazer para a historiografia os aspectos do cotidiano, das pessoas "comuns" (e não apenas dos "heróis"), e, com isso, abre-se espaço para a história das mulheres. Parte-se do pressuposto história das mulheres precisa ir ganhando as ruas, como bem salientou Perrot (2012).

Nesse contexto, defende-se que essa história deve estar presente nas escolas, nos livros didáticos, nas conversas, bem como em outros espaços de discussão, pois a história das mulheres tem um compromisso com o presente, ou seja, interroga o passado, tomando como referência questões que fazem parte de nossa vida, como a existência de desigualdades de gênero, as manifestações da sexualidade, o papel da família, do Estado, da religião, entre outras (PERROT, 2012).

\section{HISTÓRIA DAS MULHERES COMO OBJETO DA HISTORIOGRAFIA: HISTÓRIAS DAS MULHERES NO BRASIL}

É difícil escrever uma história das mulheres, já que o silêncio sobre elas foi mantido durante séculos. Há dificuldade em encontrar registros, visto que arquivos e muitos dos seus vestígios foram apagados e excluídos, uma vez que a história tradicional não considerava a presença feminina importante. No Brasil, a produção historiográfica que vai analisar este tema, irá resgatar "vários aspectos da condição feminina que variam do século XIX até meados do século XX, como: ama-de-leite, operária, prostituta, solteirona, entre outros" (CUNHA, 2000, p. 143).

Nesse contexto, percebe-se que a imagem que se reproduzia da mulher, de modo geral, na historiografia, não estava de fato relacionada a papéis ativos, significativos ou ditos "importantes" na vida pública da sociedade. A mulher era então representação como subjugada, como desprovida de potencialidade para exercer outras funções, além das domésticas. Assim, foi se construindo a imagem de exclusão, diferença e inferioridade feminina.

A importância que a história das mulheres recebeu em outros países teve um primeiro despertar aqui no Brasil no final de 1970. A Fundação Carlos Chagas, a partir de 1978, que recebeu o patrocínio da Fundação Ford, deu apoio a várias pesquisas que tratavam do tema sobre as mulheres.

Na década de 1970 a produção historiográfica será
fortemente marcada pela influência marxista, que vê a
opressão feminina em função do capitalismo, e a pers-
pectiva de análise será o mundo do trabalho. Na década
seguinte ocorre uma inovação nos estudos sobre a mu-
Iher, mediante a utilização do gênero como categoria
de análise, procurando incorporar o estudo relacional
entre homens e mulheres [...]. (SILVA, 2008, p. 226).

Inserir as mulheres na história foi avançar por um caminho até então desconhecido, como escrever, por exemplo, sobre sua vida privada, cotidiana, que pouco tiveram importância para a historiografia tradicional. Segundo Bosi (1995, p. 227), “[...] foi preciso ir ao fundo das casas, às cozinhas e oficinas, àqueles lugares onde se movem as figuras menores e furtivas". Para tanto, buscou-se nas correspondências de famílias, nos diários, nas fotografias, nos registros escritos por elas, subsídios pra representação de sua história. 
Segundo Silva (2008), as primeiras narrativas históricas sobre as mulheres no Brasil determinavam as marcas de opressão e dominação que as mulheres sofreram ao longo do tempo, não colocando a questão da resistência, de suas lutas e manifestações que elas fizeram pra fugir da subordinação masculina. A análise de Rago (1995, p. 82) irá constatar, que

É ao longo da década de 1980, porém, que emerge o que se poderia considerar uma segunda vertente das produções acadêmicas sobre as mulheres. Aí floresce um conjunto de estudos preocupados em revelar a presença das mulheres atuando na vida social, reinventando seu cotidiano, criando estratégias informais de sobrevivência, elaborando formas multifacetadas de resistência à dominação masculina e classista. Confere-se um destaque particular à sua atuação como sujeito histórico, e portanto, à sua capacidade de luta e de participação na transformação das condições sociais de vida.

Além desses fatores, a história das mulheres vai se beneficiar das fontes literárias impressas, tais como os romances, biografias, jornais e revistas, que abriram um vasto território de pesquisas, permitindo explorar vários aspectos da vida social, conforme descreveu Del Priore (1998, p. 228).

Verifica-se, assim, que foram surgindo novas abordagens, técnicas e fontes que permitiram ampliar a história, inserindo a história das mulheres. A partir dessa perspectiva, pode-se utilizar da história oral para resgatar a memória daquelas que até então estavam silenciadas. A História oral foi uma oportunidade para que fossem ouvidas as vozes daquelas que nunca tiveram a chance de se pronunciar. Assim, percebeu-se que as mulheres podiam fazer e escrever História. Verificou-se, que as mulheres também precisam ter suas memórias guardadas, tanto quanto os homens.

\section{A CINJVISIBILIDADE DA MULHER NO ENSINO DE HISTÓRIA}

As mulheres foram, durante muito tempo relegadas ao esquecimento pela historiografia tradicional, porém, na prática elas nunca estiveram ausentes da história. Nos livros didáticos, e, por conseqüência nas salas de aula, percebe-se que as mulheres aparecem de forma desigual em relação aos homens. Desse modo, pergunta-se se é possível, nas aulas de história, desnaturalizar essa desigualdade.

O que se pretende não é uma discussão a parte, colocar história das mulheres como item diferenciado no currículo de História, mas inseri-las nas aulas como participantes do processo histórico. Colocá-las de modo fracionado, fragmentado, apenas continuaria, anulando a representação das mulheres no coletivo da humanidade, partícipe da história de toda a sociedade.

Leite (2010, p. 193) induz à reflexão quando coloca algumas questões a respeito do gênero na sala de aula: "Como trabalhar a noção de gênero na aula de História sem que pareça apenas uma curiosidade? Como usar o livro didático para discutir as relações de gênero?" Leite (2010) afirma ainda que para compreender as relações de gênero na sala de aula, precisamos entender que as relações entre os homens e mulheres passam por diferenças, são construções históricas e não devem ser naturalizadas.

Dessa forma, para tornar a mulher visível na História, é importante investigar a memória feminina em diferentes fontes históricas, muitas vezes quase sempre pouco tradicionais. Podemos destacar vários temas para estudarmos a história das mulheres, sejam eles sobre a sexualidade, família, crianças, classes sociais, poder, sociedade, dentre tantos outros (PERROT, 2012). Para Leite (2010), problematizar as lutas que as mulheres tiveram de enfrentar e ainda enfrentam para superar um sistema no qual eram vistas sempre como submissas e exploradas e como conseguiram se tornar visíveis na História, faz parte de um processo de construção de uma análise crítica sobre os usos do passado.

\section{E ONDE ESTÃO AS MULHERES, NOS LIVROS DIDÁTICOS?}

É fato consumado que, ainda, o livro didático é o suporte sobre o qual grande parte dos professores organiza suas aulas. Nesse contexto, "O livro didático tem 
se constituído na atualidade, como o material didático mais presente nas salas de aula dos diferentes níveis de ensino das escolas" (BITTENCOURT, 2010, p. 545).

O livro didático é, assim, "apoio pedagógico, mas antes disso ele é mercadoria, é veículo de transmissão de ideologias, valores, representa um determinado grupo social e tem que ser analisado como tal" (FERREIRA, 2005, p. 69). Desse modo, é preciso levar em conta que os conteúdos que existem no livro didático, não são verdades absolutas. Faz-se preciso questionar, analisar criticamente os conteúdos que nele estão incluídos, pois estes trazem diferentes versões de uma mesma história.

No Brasil, as políticas públicas utilizadas para o livro didático, são representadas pelo Programa Nacional do Livro Didático (PNLD). Este programa foi criado em 1985 e tem como função avaliar e distribuir gratuitamente os livros didáticos nas escolas públicas do país. Diante disso, é preciso considerar que quando autorizado pelo PNLD os livros didáticos não se tornam um método pelo qual é preciso seguir estritamente. "Mesmo aprovado, ele traz consigo toda uma ideologia implícita, interesses capitalistas das editoras e opções teóricas, metodológicas e de conteúdos por parte dos autores e equipes editoriais" (FERREIRA, 2005, p. 70).

Verifica-se, portanto, que houve grandes mudanças em relação aos livros didáticos, entretanto, a pergunta que aqui se coloca é: Como esses livros vêm abordando a história das mulheres e as questões de gênero? Para Leite (2010) partir da compreensão histórica das relações de gênero, o professor pode redimensionar sua prática, questionando a importância de determinados conteúdos, refletindo sobre sua compreensão sobre o passado e sobre sua relação com o planejamento e o uso do livro didático. "Há, portanto, a necessidade de desenvolvimento do uso crítico do livro didático por parte do professor junto com os alunos” (LEITE, 2010, p. 201).

\section{A PESQUISA: DISCUSSÃO E RESULTADOS}

Além da revisão de literatura, para o presente, realizou-se também a análise e três livros didáticos da disciplina de História, conforme já anunciado anterior- mente. A parte de tal análise buscou-se a compreensão dos modos pelos quais as mulheres foram representadas nesses livros didáticos. Foram selecionados para a realização este estudo, três livros do ensino médio que tratavam sobre a História do Brasil. Os livros apurados foram: História do Brasil (FREIRE; ORDOÑEZ, 1974); História das Sociedades Americanas (AQUINO; LEMOS, 1981); e História - Ensino Médio (BONINI; CARDOSO; FRANCISCO; SAGATI; DIAS; CANHA, 2006).

0 primeiro livro a ser analisado foi História do Brasil, de Maria Célia Freire e Marlene Ordoñez. Produzido pela Editora Ática em 1974, estava em sua $6^{a}$ edição e possui 198 páginas. Na capa encontra-se a informação de que o livro é destinado para o ensino no segundo grau e para vestibulares. É um livro de tamanho pequeno, sem imagens na capa e ou no decorrer dos capítulos, contendo apenas alguns mapas conforme os temas que são apontados. Há atividades no final de cada capítulo, com perguntas que incitam a memorização do conteúdo estudado.

$\mathrm{Na}$ primeira parte do livro, mais especificamente no capítulo intitulado 0 Povoamento tem-se a sensação de que o texto trará participação das mulheres na história, pois, nesse capítulo fala de como viviam as pessoas que habitavam a América Portuguesa. No subtítulo Vida Social, Freire e Ordoñes (1974) descrevem quais eram as funções das mulheres nessa América, citando os trabalhos domésticos a confecção de redes e objetos de barro e a prática da agricultura. Percebe-se que a mulher ocupa somente uma pequena citação no contexto, citação esta na qual sua função era voltada para trabalhos domésticos.

Ainda nesse livro há uma citação das mulheres em um capítulo posterior. No capítulo que discute sobre a Evolução social da Colônia, a mulher foi retratada apenas na primeira página, onde autoras novamente apresentam qual a função da mulher, porém, na sociedade: "A menina era educada em casa e aprendia a cantar, ler, escrever, tocar algum instrumento e costurar. A moça tinha de escolher entre as alternativas de casar ou ir para o convento" (FREIRE; ORDOÑES, 1974, p. 77). Nota-se que essa mulher não é a mulher nativa, mas sim a mulher europeia, instalada no país. 
Nota-se que ao falar sobre a vida das mulheres no Brasil, as autoras não fazem distinções, passando a falsa sensação de que a vida de todas elas era do mesmo modo. Existia, contudo, uma naturalização da divisão de classes, baseada na economia e na etnia, sendo que essa divisão estabelecia diferenças nos aspectos educacionais, sociais e principalmente culturais. Para Stamatto (2002), as mulheres ficaram logo exclusas do sistema escolar estabelecido na colônia. Podiam, quando muito, educar-se na catequese. Estavam destinadas ao lar: casamento e trabalhos domésticos, cantos e orações, controle de pais e maridos.

As autoras do livro não problematizaram a história das mulheres, citando-as apenas duas vezes no conteúdo que diz respeito à História do Brasil. Essas citações são colocadas de modo a enfatizar as diferenças entre homens e mulheres, sobre suas distintas funções e participação nas atividades sociais. Quando a mulher aparece nas citações, esta é representada pelo seu papel no âmbito familiar, na obrigação cuidar da casa, marido e filhos. A mulher não é mencionada nos aspectos relacionados à construção social, política ou econômica.

Este livro didático foi publicado na década de 1970. Ainda nessa década a historiografia trata a questão das mulheres relacionada à família, fora disso, as mulheres não eram retratadas. Nesse contexto, pois, as mulheres, representadas pela historiografia, não tinham influência na construção da sociedade. Dessa forma, o livro didático está reduzindo as ideologias do período no qual foi produzido.

A segunda obra analisada foi escrita por Rubim Santos Leão de Aquino, Nivaldo Jesus Freitas de Lemos e Oscar Guilherme Pahl Campos Lopes. Foi publicado pela Editora Livraria Eu e você, no ano de 1981, intitulada História das Sociedades Americanas. 0 livro possui 400 páginas e traz na capa algumas imagens que fazem referência aos assuntos que o livro abordará, como por exemplo, a escravidão, o processo de independência das treze colônias inglesas da América do Norte, a Revolução Cubana, o Peronismo. No decorrer dos capítulos existem muitos mapas, documentos, fotos e charges. Ao final de cada unidade, há atividades intituladas "destaques da unidade", que são questões que dizem respeito ao conteúdo discutido anteriormente, entretanto, essas perguntas não estimulam a reflexão, e remetem à memorização.

Na unidade I, no capítulo recebe o nome de: Somos parte da Terra e Ela é parte de nós - Os primeiros povos Americanos. Na página 7, os autores trazem uma citação de Meggers que faz um breve relato de como viviam os primeiros povos da América, e, nesse momento eles abordam como era o modo de vida das mulheres:

\begin{abstract}
Os homens eram principalmente caçadores, e as mulheres coletavam provavelmente plantas selvagens comestíveis e executavam tarefas domésticas, tais como a preparação de peles para usar como proteção contra o vento, a chuva e o frio, e o trançado de cestos. (MEGGERS, 1979 apud AQUINO; LEMOS; LOPES, 1981).
\end{abstract}

Nesse contexto, tem-se a menção à divisão de trabalho dos povos indígenas, relacionada ao trabalho dos homens, separando-os, os homens um lado e as mulheres de outro. Em seguida, os autores afirmam que "aos homens cabiam a caça e a pesca; às mulheres, a coleta de raízes comestíveis e o cultivo de plantas selvagens [...]” (1981, p. 10). No decorrer do livro, buscando especialmente sobre a história do Brasil, percebe-se que os autores falam pouco sobre o nosso país, dando destaque maior à participação dos Estados Unidos na história.

O Brasil não tem, no livro, capítulos para a própria história e aparece sendo citado dentre os capítulos de uma forma geral. Após a análise de todo o livro, percebeu-se que é praticamente nula a presença das mulheres no texto, sendo que estas aparecem apenas nos capítulos introdutórios do livro. No restante do livro não há representações da figura da mulher. Compreende-se que em tal perspectiva, a mulher não estava inclusa nos movimentos sociais e nas lutas pela igualdade. Dessa forma, o material é sustentado por uma narrativa onde o homem aparece sendo o único agente da história. Desse modo, é possível afirmar que o livro didático analisado não abordou a história das mulheres, estando ainda em conformidade com as ideologias vigentes. 
É, de acordo com Cainelli (2012), somente no final da década de 1980 que começam a ocorrer visíveis mudanças no que concerne aos conteúdos e ideologias veiculados nos livros didáticos, bem como em relação ao ensino de história.

[...] Conjuntamente com as mudanças políticas no Brasil , há um movimento de reformulação da forma de ensinar História no ensino fundamental. Começa-se a pensar o professor e o aluno como sujeitos do conhecimento e a escola como um espaço de produção de conhecimento e não apenas como um lugar de disseminação de conhecimentos produzidos. (CAINELLI, 2012, p. 169).

O terceiro e último analisado foi o livro produzido pela Secretaria de Estado de Educação do Paraná, no ano de 2006, que possui um total de 376 páginas. Os autores responsáveis por sua produção foram Altair Bonini, Fábio de Oliveira Cardoso, Marli Francisco, Siumara Sagati, Sueli Dias e Vanderleia Canha. O livro é dividido por capítulos que abordam os temas a partir dos conteúdos estruturantes: Relações de Trabalho, Relações de Poder e Relações Culturais. Na apresentação do livro, os autores relatam que os capítulos trazem questões problematizadoras vinculadas aos conteúdos e ao contexto socioeconômico, político e cultural. Os autores procuraram elaborar atividades que possibilitem a reflexão, por meio da análise de documentos escritos, materiais, orais entre outros.

No primeiro capítulo, que aborda as Relações de Trabalho, as mulheres são citadas quando se trata sobre a divisão sexual do trabalho:

[...] Nas sociedades industriais, de modo geral, esperava-se que as mulheres ficassem reservadas ao mundo doméstico privado, cuidando das crianças, velhos e inválidos, realizando tarefas para o consumo do grupo familiar. Nestas mesmas sociedades, reservou-se aos homens as atividades relacionadas ao mundo público, realizando tarefas de produção social e de direção da sociedade. Sob essa lógica, o trabalho das mulheres, foi, muitas vezes, marginalizado. (BONINI; CARDOSO et al., 2006, p. 25).

Verificou-se que os autores analisam a divisão do trabalho das mulheres de forma diferente dos livros anteriormente analisados. 0 presente texto aponta para a margnalização do trabalho das mulheres, e que mesmo exercendo diferentes tarefas, as mulheres não eram reconhecidas/valorizadas, em relação aos homens.

Nas páginas que se seguem, mais precisamente no capítulo que fala sobre a construção do trabalho assalariado, os autores abordaram essa questão com mais clareza e trazem consigo um subtítulo com o nome: $\boldsymbol{O}$ trabalho feminino. A abordagem traz a condição da mulher trabalhadora no processo histórico. Como complemento, os autores trazem a indicação de dois outros textos. 0 primeiro é de Edward Thompson, na qual os autores fazem uma citação de sua obra: Costumes em comum. 0 segundo texto é do autor Carlos Bauer: Breve história da mulher no mundo ocidental. Por meio desses dois textos, os estudantes podem ter uma visão maior sobre o que está sendo trabalhado e também possuem diferentes versões do trabalho feminino no decorrer da história.

No capítulo intitulado Relações de dominação e resistência no mundo do trabalho contemporâneo (Séculos XVIII e XIX), as mulheres estão também presentes. As mulheres são mencionadas nas lutas de igualdade da Revolução Francesa, nas lutas da América Inglesa. Os autores tem a sua fala embasada e em historiadoras que discutem o tema, como Michelle Perrot, Carla Pinsky e Joana Pedro. Diferentemente do apresentado nos livros anteriores, os autores pontuam que as mulheres não ficavam restritas apenas ao espaço doméstico, mas que elas lutavam pelos seus direitos. Os autores apontam ainda, mesmo que sucintamente, as desigualdades entre o trabalho feminino e o masculino.

Os autores deste livro, finalizando o primeiro conteúdo estruturante (sobre as questões de trabalho), passam a discutir sobre outro conteúdo estruturante, que tratou sobre as relações de poder. No decorrer desses capítulos as mulheres não são retratadas. No entanto, as mulheres, aparecerão ainda diversas vezes, na medida em que o conteúdo estruturante se direciona para as relações culturais da antiguidade e na sociedade medieval europeia. Não nos alongaremos nesse tópico por não ser este o objeto do presente estudo.

Foi possível, chegando ao final da análise de cada livro didático, verificar que o livro de Maria Célia Freire e Marlene Ordoñez (1974) faz somente duas referências à 
participação das mulheres na história. As autoras separaram a história das mulheres em relação aos homens, como se elas tivessem existido em uma sociedade diferente a da masculina. Quando representadas no livro didático, são referenciadas ligadas ao trabalho doméstico e com uma vida em segundo plano, sendo importante apenas saber as tarefas que agradavam seu marido.

O livro didático de Freire e Ordoñes omitiu a vivência da história das mulheres, sendo que prevaleceu nesse livro didático apenas a descrição daquilo que os homens determinavam para o gênero feminino. Dessa forma, percebe-se que as mulheres foram representadas pelo viés da invisibilidade, como inferior ao gênero masculino. 0 livro de Rubim Santos Leão de Aquino, Nivaldo Jesus Freitas de Lemos e Oscar Guilherme Pahl Campos Lopes (1981), também não difere muito do primeiro analisado. Embora as mulheres apareçam mais vezes no decorrer desse livro, os autores citam-nas apenas de maneira superficial.

O último livro analisado, da Secretaria de educação do estado do Paraná apresenta uma diferença em relação aos dois livros anteriores, por ter sido reproduzido já no ano de 2006. Nessa época a história da mulher nessa década já havia dado um grande salto com relação ao período de publicação e veiculação dos outros livros didáticos. Dessa forma, o livro didático de 2006, contou com novos temas, novos objetos de pesquisa e novas abordagens, fato que mostra a importância que o estudo da história das mulheres, foi adquirindo com o passar dos anos. Por isso, esse livro aborda diferentes temáticas sobre a história das mulheres, não as representando como coadjuvantes do processo histórico.

\section{ALGUMAS CONCLUSÕES POSSÍVEIS}

Após a análise dos livros didáticos percebeu-se os modos pelos quais a história e os livros didáticos representavam as mulheres, bem como as ideologias vigentes na sociedade e reproduzidas nos discursos das aulas de História. Verificou-se que no livro texto da década de 1970 e no livro da década de 1980 as mulheres eram apenas citadas. Não se dava, nessa época, importância a sua participação na vida social, cultural, política e econômica, relegando-as à segundo plano, quando não ao esquecimento. No entanto, as mulheres já apareciam, mesmo que de forma breve, nos textos, o que nos leva a acreditar que esses livros didáticos já começam a apresentar as mulheres como parte da história.

Atualmente, tem-se a compreensão de que essa forma de representação das mulheres é equivocada. Tal representação do gênero feminino reduziu demasiado o papel das mulheres, uma vez que estas sempre estiveram presentes em todos os âmbitos sociais, ao longo dos séculos.

No livro didático de 2006 foi possível perceber que a história das mulheres foi introduzida, representando-as não apenas como um apêndice da história. 0 livro traz reflexões e menções às pesquisas que emergiram sobre as mulheres, além de que, ao longo dos capítulos, trouxe uma representação da mulher como ativa e participante de todos os processos sociais.

Acredita-se, portanto, que o ensino de História pode abrir inúmeras possibilidades de leitura e compreensão a respeito da história das mulheres, contudo, cabe ao professor trabalhar diferentes temas e introduzir as mulheres juntamente com os conteúdos que estão sendo trabalhados, reconhecendo assim, as atuações femininas que estão presentes nos períodos históricos.

\begin{abstract}
[...] Temáticas como mulheres, crianças, religiosidades e porque não dizer temas relacionados à própria estrutura do conhecimento histórico como fontes, documentos e temporalidade começam a fazer parte dos conteúdos em História, sendo que de forma lenta as mudanças atingem também os manuais didáticos. No entanto, é preciso levar em consideração que apenas as mudanças na forma de produzir o conhecimento histórico, ou seja, as mudanças historiográficas não proporcionam modificações substanciais na forma de ensinar história. É necessário um movimento articulado entre as renovações da historiografia e as renovações na forma de ensinar História para que haja significativamente uma mudança na forma de seleção dos conteúdos. (CAINELLI, 2012, p. 168-169).
\end{abstract}

Desse modo, acredita-se que o livro didático pode ser um dos recursos, mas não o único, quando se objetiva uma educação para a criticidade e autonomia. 
Nesse sentido o professor, mais do que reprodutor dos conhecimentos (e ideologias) do livro didático, deveria ser um dos seus intérpretes, e assim atuar numa relação dialógica com os estudantes e com os conteúdos definidos pelo currículo escolar.

\section{REFERÊNCIAS}

BARDIN, L. (2006). Análise de conteúdo. Lisboa: 70. (Obra original publicada em 1977).

BITTENCOURT, C. Livros didáticos entre textos e imagens. In: BITTENCOURT, C. (Org.). 0 saber histórico na sala de aula. São Paulo: Contexto, 2002. p.69-90.

BITTENCOURT, Circe Fernandes. Livros didáticos de história: práticas e formação docente. In: DALBEN, Ângela Imaculada Loureiro de Freitas; et al. (Org.). Convergências e tensões no campo da formação e do trabalho docente. Belo Horizonte: Autêntica, 2010. p.544-563.

CAINELLI, Marlene. A escrita da história e os conteúdos ensinados na disciplina de história do ensino fundamental. Educação e Filosofia, Uberlândia, v.26, n.51, jan-jun. 2012. Disponível em: <http://www.seer.ufu.br/index.php/

EducacaoFilosofia/article/viewFile/7666/9694>. Acesso em: 28 out. 2015.

CUNHA, Maria de Fátima da. Mulher e historiografia: da visibilidade á diferença. Hist. Ensino, Londrina, v.6, p.143, out. 2000. Disponível em: <www.uel. br/revistas/uel/index.php/histensino/article/ view/12396/10864>. Acesso em: 20 jan. 2015.
DEL PRIORE, Mary. História das mulheres: as vozes do silêncio. In: FREITAS, Marcos Cezar de (Org.).

Historiografia brasileira em perspectiva. SP:

Contexto, 1998.

FERREIRA, Angela Ribeiro. Representações da história das mulheres no Brasil em livro didáticos de história. 2005. Dissertação (Mestrado) - UEPG, Ponta grossa, 2005.

PERROT, Michelle. Minha história das mulheres. São Paulo: Contexto, 2012.

RAGO, Margareth. As mulheres na historiografia brasileira. In: SILVA, Zélia Lopes (Org.). Cultura

histórica em debate. São Paulo: UNESP, 1995.

SILVA, Tânia Maria Gomes da. Trajetória da historiografia das mulheres no Brasil. Politeia, Vitória da Conquista, v.8, n.1. 2008. Disponível em: <http://periodicos.uesb.br/index.php/politeia/ article/viewFile/276/311>. Acesso em: 28 out. 2015.

STAMATTO, Maria Inês Sucupira. Um olhar na história: a mulher na escola (Brasil: 1549 - 1910). II Congresso Brasileiro de História da Educação: História e memória da educação brasileira. Anais..., Natal-RN, nov 2002. Disponível em: <http:// www.sbhe.org.br/novo/congressos/cbhe2/pdfs/ Tema5/0539.pdf>. Acesso em: 22 jan. 2015. 
1 Especialista em Metodologia do Ensino de História e Geografia pelo Centro Universitário Internacional - UNINTER; Graduada em História (Licenciatura Plena) pela Universidade Estadual do Norte do Paraná - UENP). E-mail: amalia_rambaldi@hotmail.com

Recebido em: 03 de novembro de 2015 Avaliado em: 31 de março de 2017 Aceito em: 05 de maio de 2017
2 Doutoranda em Educação - Doutorado em Educação da Universidade Tuiuti do Paraná - UTP; Mestre em Educação pela Universidade Regional de Blumenau - FURB; Graduada em Pedagogia pela Universidade Regional de Blumenau - FURB; Licenciada em História pelo Centro Universitário Leonardo da Vinci - UNIASSELVI. E-mail: mel.probst@gmail.com. 
